\title{
A Note on the Surface Deterioration of Scrimber Composites Exposed to Artificial Ageing
}

\author{
Minzhen Bao ${ }^{1} \oplus$, Fei Rao ${ }^{1,2} \oplus$, Sheng $\mathrm{He}^{1}$, Yongjie Bao ${ }^{1}$, Zaixing $\mathrm{Wu}^{1}{ }^{1}$, $\mathrm{Neng}^{\mathrm{Li}}{ }^{1, *}$ and \\ Yuhe Chen ${ }^{1, *}$ \\ 1 Key Laboratory of High Efficient Processing of Bamboo of Zhejiang Province, China National Bamboo \\ Research Center, Hangzhou 310012, China; baominzhen@caf.ac.cn (M.B.); raofei1991@sina.com (F.R.); \\ hesheng_cbrc@163.com (S.H.); baoyongjie1@126.com (Y.B.); jansonwu@126.com (Z.W.) \\ 2 Research Institute of Wood Industry, Chinese Academy of Forestry, Beijing 100091, China \\ * Correspondence: lineng@caf.ac.cn (N.L.); yuhec@caf.ac.cn (Y.C.)
}

Received: 1 November 2019; Accepted: 9 December 2019; Published: 10 December 2019

\begin{abstract}
The effect of ultraviolet radiation on the surface deterioration of scrimber composites with different densities and levels of resin content was investigated for this paper. The surface color, gloss, roughness, and wettability of the samples were investigated to determine the extent of surface changes due to accelerated ageing. The results indicated that all scrimber composites exhibited variation in the color of their surfaces during artificial xenon light exposure. After artificial accelerated ageing, the surface contact angle and roughness were found to increase, whereas the surface gloss and surface free energy decreased. Furthermore, it was observed that the density and resin content of the scrimber composites contributed to reductions in their color variation, wettability, and roughness during weathering, which suggested that the density and resin content played important roles in determining their surface photodegradation properties. Artificial ageing resulted in the degradation of lignin and hemicellulose, thus causing severe surface characteristics.
\end{abstract}

Keywords: scrimber composites; ageing; artificial xenon light; surface properties

\section{Introduction}

It is well-established that wood has been widely exploited as an engineering material. As sources of naturally grown wood have been continuously subjected to an increasing consumption, fast growing wood is expected to be employed as a substitute for building structures. Scrimber composites are oriented, fast-growing wood strand mats arranged in parallel with phenol formaldehyde (PF) resin under high pressure [1]. Owing to the compression of the wood strand mats and the bonding of the adhesive, the wood cells are densified and bonded with the adhesive [1]. The modulus of rupture and the modulus of elasticity of scrimber composites can attain values of up $201 \mathrm{MPa}$ and $17.7 \mathrm{GPa}$, respectively [1]. The water resistance and mechanical properties of the scrimber could satisfy the requirements for outdoor floor covering, as specified by GB/T 30364-2013 for "bamboo scrimber flooring" [2]. There are several scrimber factories with the ability to produce $160,000 \mathrm{~m}^{3}$ of boards yearly in China. Scrimber composites are considered to be suitable biological materials for outdoor applications and are readily available at markets in China [3].

When wood and wood-based materials are exposed to outdoor ageing conditions, color changes, and visible cracks are bound to occur on their surface [4,5]. Some environmental factors, such as solar radiation, moisture, oxygen, and temperature, can contribute to the degradation of wood surfaces. Among the aforementioned parameters, ultraviolet (UV) radiation has the most damaging effect on the aging of wood. Though the UV radiation constitutes only $5 \%$ of the total energy of sunlight, it can generate free radicals and destroy major wood components $[4,6]$. Lignin is the most sensitive 
component, contributing $80-95 \%$ of the UV absorption coefficient $[4,5,7,8]$. These ageing conditions have an influence on the outdoor service life of wood and wood-based materials.

Wood and wood-based materials' degradation rate depends on the materials' properties, such as density and moisture content. The density affects the spreading rate of the degradation and the extent of photodegradation during ageing [9]. With an increase in the resin content, the dimensional stability has been found to improve [2]. Previous research has indicated that the effectiveness of low molecular weight PF resin as a photoprotective treatment for wood can be improved by increasing the concentration of PF resin and by combining it with a water-soluble, hindered amine light stabilizer [6]. However, changes in the surface characteristics of scrimber composites during ageing have not been adequately studied. Scrimber composites can be used in different environments to adjust densities and resin content. However, the effects of density and resin content on the surface characteristics of wood scrimber composites under light have not been further investigated. Therefore, it is possible that the photostability of the surface of scrimbers might be affected by their resin content and density.

In this study, the surface properties of scrimber composites were investigated before and during artificial ageing with regard to their color, gloss, roughness, and wettability. The surface chemical changes of the scrimber composites were characterized by attenuated total reflectance (ATR) Fourier-transform infrared (FTIR) spectroscopy. These analytical techniques can provide insights into the changes of the surface characteristics of scrimber composites under UV irradiation, as well as technical support for outdoor applications.

\section{Materials and Methods}

\subsection{Preparation of Scrimber Composites}

Scrimbers were prepared according to the previously published literature [1]. Six-year-old poplar wood (Populus spp.) was obtained from the market and peeled into veneers of $6 \mathrm{~mm}$ thicknesses after debarking; it was then split along the grain direction into strand mats. Subsequently, the mats were air-dried to achieve a moisture content (MC) of $12 \%$ and impregnated with PF resin (a solid content of $20 \mathrm{wt} . \%$ ) for approximately 3-8 min to attain the target resin content. The impregnated mats were dried in a kiln at $40{ }^{\circ} \mathrm{C}$ to obtain a $12 \% \mathrm{MC}$ and weighed to obtain the target density. The mats were assembled along the grain direction in the mold. Hot pressing was conducted at $140{ }^{\circ} \mathrm{C}$ under $5.0 \mathrm{MPa}$ for $30 \mathrm{~min}$ to obtain a scrimber panel $(450 \mathrm{~mm} \times 160 \mathrm{~mm} \times 18 \mathrm{~mm})$. Scrimber panels with different densities $\left(0.85,1.00\right.$ and $\left.1.15 \mathrm{~g} / \mathrm{cm}^{3}\right)$ were prepared with a $13 \%$ resin content, and panels with different levels of resin content $(8 \%, 13 \%$ and $18 \%)$ were prepared with a density of $1.00 \mathrm{~g} / \mathrm{cm}^{3}$. Six replicates were carried out for each group. All scrimber panels were conditioned in a chamber at a relative humidity of $65 \% \pm 5 \%$ under a temperature of $20 \pm 2{ }^{\circ} \mathrm{C}$ for 2 weeks before being tested.

\subsection{Artificial Ageing}

The as-obtained scrimbers $(80 \mathrm{~mm} \times 40 \mathrm{~mm} \times 18 \mathrm{~mm})$ were fixed in stainless steel holders and irradiated with fluorescent UV-visible light (UVB-313 lamp, $0.71 \mathrm{~W} / \mathrm{m}^{2}$ ) by using an accelerated UV weathering test box (Nine Rings Corp., Hangzhou, China). Accelerated weathering was carried out according to ASTM G154-12a [10]. Each cycle of simulated weathering conducted for $8 \mathrm{~h}$, involved a light irradiation and condensation of $4 \mathrm{~h}$ at 60 and $50{ }^{\circ} \mathrm{C}$, respectively. The samples were tested after $24,72,120,168$ and $216 \mathrm{~h}$ of exposure.

\subsection{Color Determination}

The surface colors of the scrimbers tested for different periods were measured with a colorimeter (CM-3600d, Konica Minolta Inc., Kyoto, Japan). The colors were expressed by L* (bright/dark), $a^{*}$ (red/green), and $b^{*}$ (yellow/blue). The total color change $\left(\Delta E^{*}\right)$ was calculated with Equation (1):

$$
\Delta E^{*}=\sqrt{\left(\Delta L^{*}\right)^{2}+\left(\Delta a^{*}\right)^{2}+\left(\Delta b^{*}\right)^{2}}
$$


where $\Delta L^{*}, \Delta a^{*}$, and $\Delta b^{*}$ represent the total changes in $L^{*}, a^{*}$, and $b^{*}$ during the ageing test, respectively. Six replicate measurements were performed on defined points on the sample surfaces.

\subsection{Gloss Analysis}

The surface gloss values of the scrimbers were recorded with a portable universal gloss meter (Bonsai Instrument Corp., Shanghai, China). The gloss analysis was carried out according to the ASTM D523 standard [11]. The percentage gloss change $(\Delta G \%)$ was calculated with Equation (2):

$$
\Delta G \%=\frac{G_{t}-G_{0}}{G_{0}} \times 100 \%
$$

where the subscripts 0 and $t$ denote the values of the samples before and after exposure for $t(h)$, respectively. Six replicate measurements were performed on the sample surfaces.

\subsection{Roughness Analysis}

The surface roughness analysis of the scrimbers was carried out on a JB-4C precision roughness tester (Taiming Optical Instrument Corp., Shanghai, China). The data were transformed by a Gaussian filter with a cutoff wavelength of $2.5 \mathrm{~mm}$. The mean surface roughness $(\mathrm{Ra})$ was used as an indicator of the surface roughness. Six replicate measurements were performed on the sample surfaces.

\subsection{Surface Wettability}

The contact angles on the surfaces of the scrimbers were measured before and after accelerated ageing for $216 \mathrm{~h}$ with the use of a DSA 100 contact angle analyzer (Kruss, Hamburg, Germany). An automatic micro syringe was used to dispense drops of approximately $5 \mu \mathrm{L}$ of the test liquid (water, formamide, and diiodomethane). The initial contact angles of the droplets were measured on each sample. The advance software of the DSA 100 analyzer was used to obtain the contact angle. The Lifshitze-van der Waals/acid-base (LW-AB) approach was used to calculate the surface free energy $\left(\gamma_{\mathrm{S}}^{\mathrm{T}}\right)$, Lifshitze-van der Waals component $\left(\gamma_{\mathrm{S}}^{\mathrm{LW}}\right)$, the acid-base component $\left(\gamma_{\mathrm{S}}^{\mathrm{AB}}\right)$, the electron-accepting component $\left(\gamma_{S}^{+}\right)$, and the electron-donating component $\left(\gamma_{S}^{-}\right)$[12].

\subsection{FTIR Analysis}

The FTIR spectra of the air-dried scrimbers with different levels of resin content were measured before and after the accelerated ageing was conducted for $216 \mathrm{~h}$ by using a Nicolet iS10 spectrophotometer (Smart iTX, Thermo Fisher Scientific, Waltham, MA, USA) equipped with a diamond crystal ATR accessory. The spectra were recorded in absorbance units from 4000 to $800 \mathrm{~cm}^{-1}$ at a spectral resolution of $4 \mathrm{~cm}^{-1}$ with 64 scans.

\section{Results and Discussion}

\subsection{Color Changes}

Figures 1 and 2 show the color parameter changes of the scrimbers during the artificial xenon light exposure with different densities and levels of resin content, respectively. With an increase in the ageing time, all scrimbers showed a decrease in $\Delta L^{*}$ and an increase in $\Delta a^{*}$; this suggested that the scrimbers during artificial xenon light exposure turned dark and red. After $168 \mathrm{~h}$ of exposure, these values gradually became stable. The $\Delta L^{*}$ and $\Delta a^{*}$ values of the scrimbers did not significantly change as functions of the densities and resin content. An increase in the $\Delta b^{*}$ value indicated a tendency to become yellowish, while a decrease in the value indicated a tendency to become bluish. As observed, $\Delta b^{*}$ increased until $120 \mathrm{~h}$ of exposure, and it subsequently decreased with further exposure for $216 \mathrm{~h}$; this suggested that the scrimbers first turned yellow and then, blue. Notably, a high density prevented the decrease in $\Delta b^{*}$ upon UV exposure. The $\Delta E^{*}$ value reflected the severity of ageing time; 
this value increased with an increase in the ageing time. There was no apparent difference in density and resin content. Rao and Chen obtained similar results after exposing bamboo-fiber-reinforced composites with different densities to artificial sunlight [13]. The decrease in lightness and the increase in the color difference of the scrimber were primarily caused by the photodegradation of lignin [14]. Photodegradation results in the formation of new lignin chromophores, which primarily are comprised of quinone-type structures and cause discoloration [15].

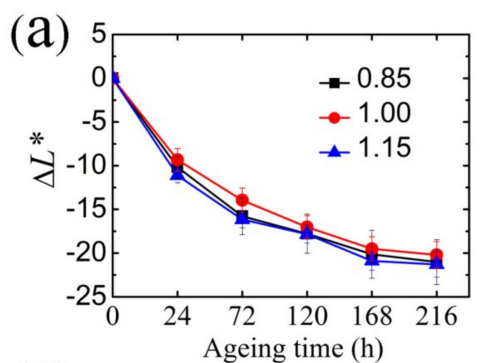

(C)

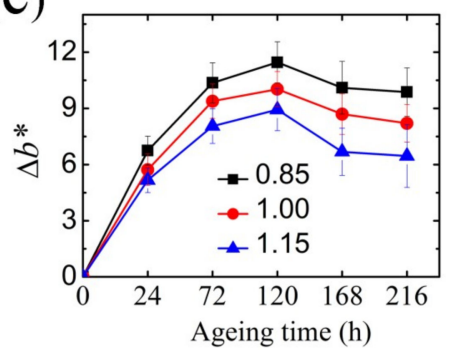

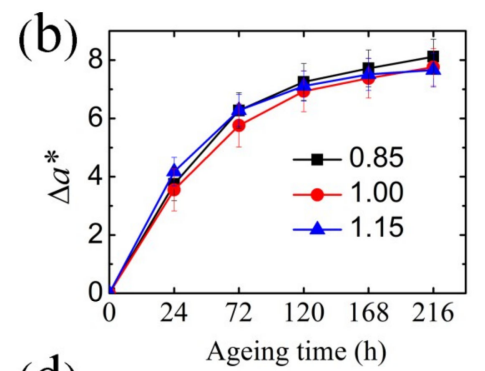

(d)

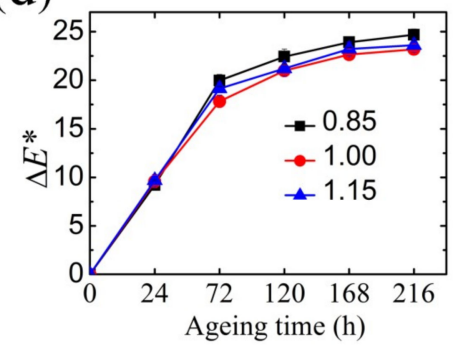

Figure 1. Color values for scrimbers with different densities during artificial ageing. (a) $\Delta L^{*}$ (change in $L^{*}$ (bright/dark)); (b) $\Delta a^{*}$ (change in $a^{*}$ (red/green)); (c) $\Delta b^{*}$ (change in $b^{*}$ (yellow/blue)); and (d) $\Delta E^{*}$ (total color change).
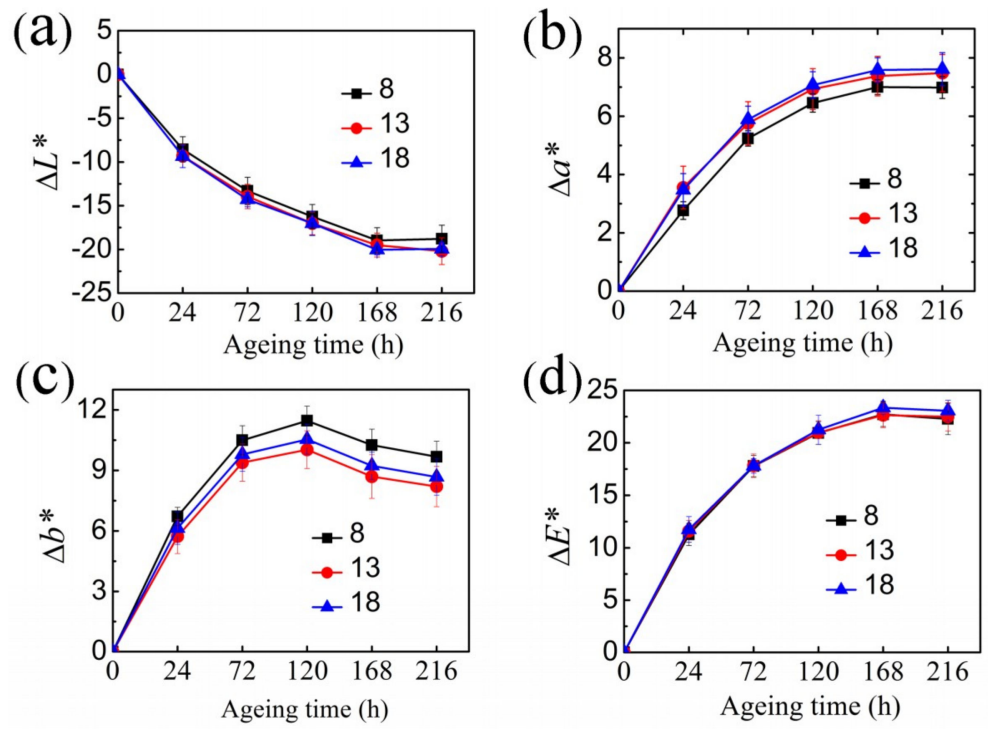

Figure 2. Color values for scrimbers with different levels of resin content during artificial ageing. (a) $\Delta L^{*}$; (b) $\Delta a^{*}$; (c) $\Delta b^{*}$; and (d) $\Delta E^{*}$.

\subsection{Gloss Changes}

Figure 3 shows the $\Delta G \%$ of the scrimbers during the artificial xenon light exposure. With increasing ageing time, all scrimbers showed a decrease in $\Delta G \%$. The loss in gloss for all scrimbers was very rapid for the first $24 \mathrm{~h}$. The gloss changes during the accelerated ageing were correlated with the density and resin content. After $216 \mathrm{~h}$ of exposure, the smallest $\Delta G \%$ values of $-56.00 \%$ and $-55.99 \%$ were observed 
for the scrimbers with a density of $1.15 \mathrm{~g} / \mathrm{cm}^{3}$ and a resin content of $18 \%$, respectively. All samples showed a significant reduction in gloss, suggesting that the scrimbers lost their gloss after ageing.
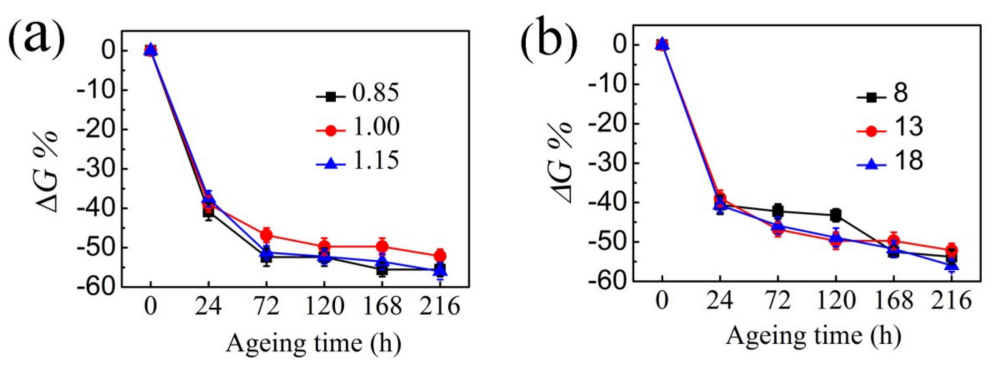

Figure 3. Changes in gloss of scrimbers with different (a) densities and (b) levels of resin content during artificial ageing.

\subsection{Roughness Changes}

The changes in Ra of the scrimbers with different densities and levels of resin content during artificial xenon light exposure are shown in Figure 4. With an increasing ageing time, all scrimbers showed an increase in Ra. After $216 \mathrm{~h}$ of exposure, the highest Ra values of 44.17 and $47.77 \mu \mathrm{m}$ were observed for the scrimbers with a density of $0.85 \mathrm{~g} / \mathrm{cm}^{3}$ and a resin content of $8 \%$, respectively. The scrimbers with a density of $1.00 \mathrm{~g} / \mathrm{cm}^{3}$ and a resin content of $13 \%$ showed the lowest $R$ a value $(19.95 \mu \mathrm{m})$ after $216 \mathrm{~h}$ of irradiation. The density and resin content affected the changes in the surface roughness during the ageing process.
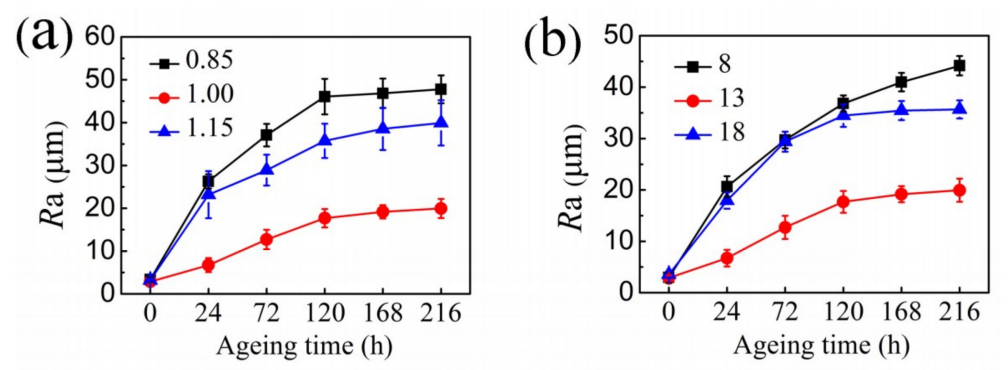

Figure 4. Changes in roughness of scrimbers with different (a) densities and (b) levels of resin content during artificial ageing.

There are several reasons for the increase in roughness after weathering. First, the surface lignin underwent degradation during the exposure treatment, and a layer of cellulose was formed on the surface [16]. Secondly, crack formation took place in the cell walls [17]. Thirdly, water accelerated the loss of the soluble lignin degradation products because the surface fibers loosened [17]. It is highly probable that moisture caused an unequal distribution of stress in the material, and this distribution resulted in surface cracks.

\subsection{Surface Wettability}

The initial contact angles for the scrimbers with different densities and levels of resin content are listed in Table 1. The contact angles on the control and weathered scrimber samples were affected by the density and resin content. The contact angles increased with the increase in the density and resin content. The higher the density and resin content of the samples, the higher the contact angles of the three liquids. This result indicated a lower wettability and was in agreement with previous studies [18]. Therefore, it can be established that the density of the samples had a significant effect on their wettability. 
Table 1. Contact angles and surface free energy components of scrimbers before and after artificial ageing.

\begin{tabular}{|c|c|c|c|c|c|c|c|c|c|c|}
\hline \multirow{2}{*}{ Samples } & \multirow{2}{*}{$\begin{array}{l}\text { Density } \\
\left(\mathrm{g} / \mathrm{cm}^{3}\right)\end{array}$} & \multirow{2}{*}{$\begin{array}{c}\text { Resin } \\
\text { Content } \\
(\%)\end{array}$} & \multicolumn{3}{|c|}{ Contact Angle } & \multicolumn{5}{|c|}{ Surface Free Energy $\left(\mathrm{mJ} / \mathrm{m}^{2}\right)$} \\
\hline & & & Water & Formamide & Diiodomethane & $\gamma_{\mathbf{S}}^{\mathbf{L W}}$ & $\gamma_{\mathrm{S}}^{+}$ & $\gamma_{\mathbf{S}}^{-}$ & $\gamma_{\mathbf{S}}^{\mathbf{A B}}$ & $\gamma_{\mathbf{S}}^{\mathrm{T}}$ \\
\hline \multirow{6}{*}{$\begin{array}{l}\text { Control } \\
\text { Samples }\end{array}$} & 0.85 & 13 & 68.36 & 81.20 & 56.92 & 30.35 & 2.92 & 42.02 & 22.16 & 52.52 \\
\hline & 1.00 & 13 & 82.14 & 82.87 & 62.36 & 27.22 & 1.12 & 19.63 & 9.39 & 36.61 \\
\hline & 1.15 & 13 & 85.13 & 83.21 & 65.59 & 25.37 & 0.63 & 15.67 & 6.30 & 31.66 \\
\hline & 1.00 & 8 & 80.08 & 80.92 & 57.43 & 30.05 & 1.45 & 21.04 & 11.07 & 41.12 \\
\hline & 1.00 & 13 & 82.14 & 82.87 & 62.36 & 27.22 & 1.12 & 19.63 & 9.39 & 36.61 \\
\hline & 1.00 & 18 & 84.20 & 83.59 & 66.41 & 24.90 & 0.68 & 17.20 & 6.84 & 31.74 \\
\hline \multirow{6}{*}{$\begin{array}{c}\text { Weathered } \\
\text { Samples }\end{array}$} & 0.85 & 13 & 83.76 & 98.54 & 54.56 & 31.70 & 9.42 & 34.29 & 35.95 & 67.65 \\
\hline & 1.00 & 13 & 85.48 & 99.90 & 59.32 & 28.96 & 8.36 & 32.40 & 32.93 & 61.89 \\
\hline & 1.15 & 13 & 101.70 & 104.10 & 60.77 & 28.13 & 6.79 & 11.90 & 17.98 & 46.11 \\
\hline & 1.00 & 8 & 82.59 & 96.06 & 53.45 & 32.33 & 8.48 & 33.55 & 33.74 & 66.07 \\
\hline & 1.00 & 13 & 85.48 & 99.90 & 59.32 & 28.96 & 8.36 & 32.40 & 32.93 & 61.89 \\
\hline & 1.00 & 18 & 89.68 & 104.90 & 62.32 & 27.24 & 9.47 & 33.85 & 34.49 & 61.09 \\
\hline
\end{tabular}

The contact angles of all liquids on the samples of the same density and resin content increased to different degrees after ageing; this suggested that the accelerated ageing significantly affected the surface wettability. The significant decrease in wettability implied a considerable reduction in hygroscopicity. These results indicated that the ageing process led to an increase in the hydrophobicity of the scrimbers, and the increase in the hydrophobicity was more for the samples with higher densities and resin content.

\subsection{Surface Free Energy}

The $\gamma_{S}^{\mathrm{T}}$ and its components are presented in Table 1 for the scrimbers before and after xenon light exposure. The $\gamma_{\mathrm{S}}^{\mathrm{LW}}, \gamma_{\mathrm{S}}^{\mathrm{AB}}$, and $\gamma_{\mathrm{S}}^{\mathrm{T}}$ of the control scrimber and the weathered scrimber samples decreased with an increase in the density and resin content. The difference among $\gamma_{S}^{\mathrm{LW}}, \gamma_{S}^{\mathrm{AB}}$, and $\gamma_{S}^{\mathrm{T}}$ for the weathered samples was greater than those for the control samples of the same density and resin content. The $\gamma_{S}^{\mathrm{LW}}$ exhibited a predominant contribution to the $\gamma_{\mathrm{S}}^{\mathrm{T}}$, which is one of the characteristics of typical polymers [19]. It was observed that $\gamma_{\mathrm{S}}^{\mathrm{LW}}$ predominantly contributed to $\gamma_{\mathrm{S}}^{\mathrm{T}}$ in the case of the control scrimber; conversely, in the case of the weathered scrimber samples, $\gamma_{\mathrm{S}}^{\mathrm{AB}}$ accounted for more than half of $\gamma_{S}^{\mathrm{T}}$. The $\gamma_{\mathrm{S}}^{\mathrm{AB}}$ referred to the interaction between hydroxyl groups of wood and the functional groups of the adhesive by forming the hydrogen bond [19]. The increase in $\gamma_{S}^{\mathrm{AB}}$ after the ageing process indicated a decreased possibility of interaction between the hydroxyl groups of wood [20]. The $\gamma_{S}^{-}$of scrimber surfaces was distinctly higher than $\gamma_{S}^{+}$, implying that the scrimbers were monopolar basic. The difference between the acid and base components was significant, and this was probably due to the changes in the hydrophobicity after ageing. Based on the above results, it can be observed that the ageing process increased the surface energy as well as all the energy components of the scrimbers.

\subsection{FTIR Spectroscopy}

The ATR-FTIR spectra of the scrimbers before and after accelerated ageing are shown in Figure 5. The changes caused by ageing were mainly observed at 3340, 2920, 1730, 1650, 1590, 1510, 1420 and $1230 \mathrm{~cm}^{-1}$. The intensities of the peaks at $3340 \mathrm{~cm}^{-1}$ (free $-\mathrm{OH}$ groups in three wood polymer components) and $2920 \mathrm{~cm}^{-1}$ ( $\mathrm{CH}$ and $\mathrm{CH}_{2}$ stretching in cellulose) for the scrimber samples with resin content of $13 \%$ and $8 \%$ were diminished after the accelerated ageing process. The intensity of the peak at $1730 \mathrm{~cm}^{-1}$ (ester carbonyl groups in hemicellulose) was reduced after the ageing process, indicating that the partial ester groups and polysaccharides were decomposed. The intensity of the peak at $1650 \mathrm{~cm}^{-1}$ (quinines and quinine methides in lignin) increased after ageing, thus indicating the oxidation of lignin [21]. The peaks at 1590 and $1510 \mathrm{~cm}^{-1}$ were caused by the $\mathrm{C}=\mathrm{C}$ aromatic ring in the lignin; the peak at $1420 \mathrm{~cm}^{-1}$ was attributed to aromatic skeletal vibrations in the lignin and the 
$\mathrm{CH}$ deformation in cellulose. Finally, the peak at $1230 \mathrm{~cm}^{-1}$ was assigned to guaiacyl ring with $\mathrm{C}-\mathrm{O}$ stretching in the lignin and hemicellulose. The intensities of these peaks significantly decreased after the accelerated ageing; this suggested that the lignin on the top surface of the scrimbers was severely damaged, which contributed to photodiscoloration. The peaks at $1320 \mathrm{~cm}^{-1}$ (crystallized cellulose I content), $1030 \mathrm{~cm}^{-1}$ (C-O stretching in cellulose), and $898 \mathrm{~cm}^{-1}$ (CH deformation in cellulose) are characteristic to cellulose. The intensities of these peaks remained almost the same after the ageing process, which indicated that ageing hardly affected the cellulose content. For the scrimbers with different levels of resin content, the intensities of peaks at 3340,2920, 1420, 1230 and $1030 \mathrm{~cm}^{-1}$ after ageing were different. It was observed that a higher resin content in the scrimber increased its stability. The FTIR results showed that the polysaccharide content and lignin were significantly reduced after the ageing treatment, and it was found that the reduction depended on the resin content.

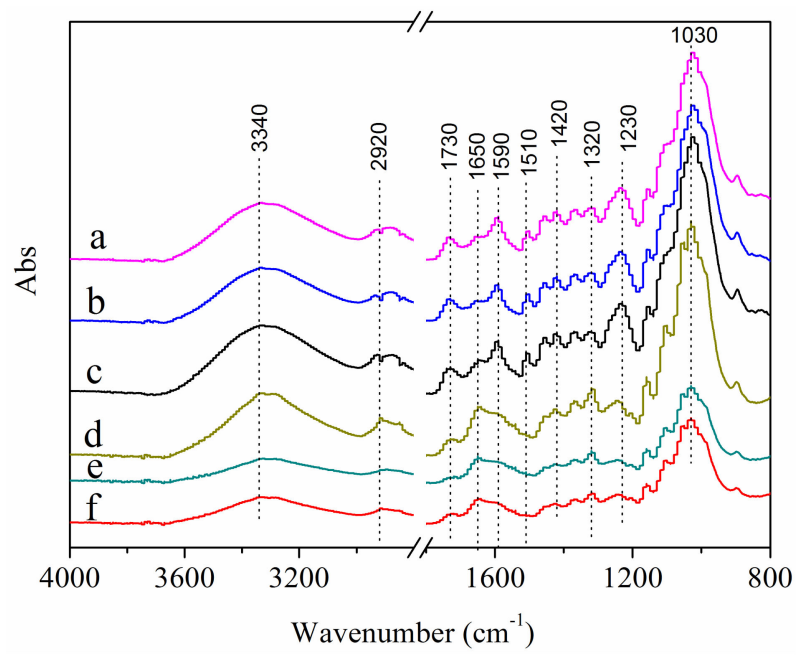

Figure 5. Attenuated total reflectance (ATR)-FTIR spectra of scrimbers before and after artificial ageing. (a) Resin content of $18 \%$; (b) resin content of $13 \%$; (c) resin content of $8 \%$; (d) weathered, resin content of $18 \%$, (e) weathered, resin content of $13 \%$; and (f) weathered, resin content of $8 \%$.

The decrease in the brightness and the increase in the color changes of the scrimbers were predominantly caused by the photodegradation of lignin. Photodegradation resulted in the formation of novel lignin chromophores that were primarily comprised of quinone-type structures and caused discoloration [14]. In addition, the condensation of water induced the washing out of the degradation products on the material surface, and, consequently, the underlying fresh surface was further exposed [22]. This process affected the surface smoothness, which reduced the gloss and further affected the light reflection and hydrophobicity.

\section{Conclusions}

After artificial accelerated ageing, the surfaces of the scrimber panels became darker; furthermore, their colors faded, and they turned red and blue. The surface gloss decreased, and the roughness and contact angle increased; all of this suggested that the accelerated ageing process had a significant effect on the scrimber's surface properties. Our results indicate that higher density scrimber panels and ones with a higher resin content are more resistant to accelerated weathering. In summary, our approach promotes the outdoor durability of scrimber as a base material and provides technical support for outdoor applications. However, additional research on scrimbers with surface coatings is needed for a more complete evaluation of the suitability of scrimber for outdoor applications. 
Author Contributions: Conceptualization, M.B., N.L. and Y.C.; methodology, M.B.; validation, N.L. and Y.C.; formal analysis, F.R. and S.H.; investigation, M.B. and F.R.; resources, Z.W.; data curation, F.R., S.H., Y.B. and Z.W.; writing—original draft preparation, M.B.; writing—review and editing, N.L. and Y.C.; visualization, Y.C.; supervision, Y.C.; project administration, Y.C.; funding acquisition, Y.C. and M.B.

Funding: The authors appreciate the financial support from the Promotion of Project of Forestry Science and Technology of the Chinese Forestry and Grassland Administration (2019-36) and the Fundamental Research Funds for the Non-profit Research Institution of Zhejiang Province (Study on Preparation and Application Technology of Bamboo Organic Anti-mildew Microcapsules).

Acknowledgments: The authors wish to thank Qiongxia Liu for experimental assistance.

Conflicts of Interest: The authors declare no conflict of interest.

\section{References}

1. Bao, M.; Li, N.; Huang, C.; Chen, Y.; Yu, W.; Yu, Y. Fabrication, physical-mechanical properties and morphological characterizations of novel scrimber composite. Eur. J. Wood Wood Prod. 2019, 77, 741-747. [CrossRef]

2. Zhang, Y.; Qi, Y.; Huang, Y.; Yu, Y.; Liang, Y.; Yu, W. Influence of veneer thickness, mat formation and resin content on some properties of novel poplar scrimbers. Holzforschung 2018, 72, 673-680. [CrossRef]

3. Zhang, Y.; Qi, Y.; Huang, Y.; Yu, W. Manufacturing technology, application and future development of high-performance wood scrimber in China. Chin. Wood Ind. 2018, 32, 14-17.

4. Evans, P.; Mathews, M.J.C.B.; Schmalzl, K.; Ayer, S.; Kiguchi, M.; Kataoka, Y. Weathering and surface protection of wood. In Handbook of Environmental Degradation of Materials; William Andrew Inc.: Norwich, UK, 2005.

5. Feist, W.C. Outdoor wood weathering and protection. Archaeol. Wood Prop. Chem. Preserv. 1990, 196, $263-298$.

6. Evans, P.D.; Kraushaar, S.; Cullis, I.; Liu, C.; Sèbe, G. Photostabilization of wood using low molecular weight phenol formaldehyde resin and hindered amine light stabilizer. Polym. Degrad. Stab. 2013, 98, 158-168. [CrossRef]

7. Li, N.; Chen, Y.; Bao, Y.; Zhang, Z.; Wu, Z.; Chen, Z. Evaluation of UV-permeability and photo-oxidisability of organic ultraviolet radiation-absorbing coatings. Appl. Surf. Sci. 2015, 332, 186-191. [CrossRef]

8. Li, N.; Rao, F.; He, L.; Yang, S.; Bao, Y.; Huang, C.; Bao, M.; Chen, Y. Evaluation of biochar properties exposing to solar radiation: A promotion on surface activities. Chem. Eng. J. 2019, 123353. [CrossRef]

9. Kataoka, Y.; Kiguchi, M.; Fujiwara, T.; Evans, P. The effects of within-species and between-species variation in wood density on the photodegradation depth profiles of sugi (Cryptomeria japonica) and hinoki (Chamaecyparis obtusa). J. Wood Sci. 2005, 51, 531-536. [CrossRef]

10. ASTM International. ASTM G154-12a Standard Practice for Operating Fluorescent Ultraviolet (UV) Lamp Apparatus for Exposure of Nonmetallic Materials; ASTM International: West Conshohocken, PA, USA, 2014.

11. ASTM International. ASTM D523 Standard Test Method for Specular Gloss; ASTM International: West Conshohocken, PA, USA, 2014.

12. Bao, M.; Huang, X.; Jiang, M.; Li, N.; Yu, Y.; Yu, W. Study on the changes in surface characteristics of Populus tomentosa due to thermo-hydro-process. J. Wood Sci. 2018, 64, 264-278. [CrossRef]

13. Rao, F.; Chen, Y.; Li, N.; Zhao, X.; Bao, Y.; Wu, Z.; Ren, D.; Xu, J.; Cai, H. Preparation and characterization of outdoor bamboo-fiber-reinforced composites with different densities. Bioresources 2017, 12, 6789-6811. [CrossRef]

14. Kanbayashi, T.; Kataoka, Y.; Ishikawa, A.; Matsunaga, M.; Kobayashi, M.; Kiguchi, M. Confocal Raman microscopy reveals changes in chemical composition of wood surfaces exposed to artificial weathering. J. Photochem. Photobiol. B Biol. 2018, 187, 136-140. [CrossRef] [PubMed]

15. Lin, Y.; Kringstad, K. Some reactions in the photoinduced discoloration of lignin. Nor. Skogind. 1971, 25, 252-256.

16. Cogulet, A.; Blanchet, P.; Landry, V. Wood degradation under UV irradiation: A lignin characterization. J. Photochem. Photobiol. B Biol. 2016, 158, 184-191. [CrossRef] [PubMed]

17. Wang, X.; Ren, H. Surface deterioration of moso bamboo (Phyllostachys pubescens) induced by exposure to artificial sunlight. J. Wood Sci. 2009, 55, 47-52. [CrossRef]

18. Bao, M.; Huang, X.; Zhang, Y.; Yu, W.; Yu, Y. Effect of density on the hygroscopicity and surface characteristics of hybrid poplar compreg. J. Wood Sci. 2016, 62, 441-451. [CrossRef] 
19. Mohan, T.; Kargl, R.; Doliška, A.; Vesel, A.; Köstler, S.; Ribitsch, V. Wettability and surface composition of partly and fully regenerated cellulose thin films from trimethylsilyl cellulose. J. Colloid Interface Sci. 2011, 358, 604-610. [CrossRef] [PubMed]

20. Huang, X.; Kocaefe, D.; Kocaefe, Y.; Boluk, Y.; Krause, C. Structural analysis of heat-treated birch (Betule papyrifera) surface during artificial weathering. Appl. Surf. Sci. 2013, 264, 117-127. [CrossRef]

21. Chirkova, J.; Andersone, I.; Irbe, I.; Spince, B.; Andersons, B. Lignins as agents for bio-protection of wood. Holzforschung 2011, 65, 497-502. [CrossRef]

22. Li, N.; Bao, M.; Rao, F.; Shu, Y.; Huang, C.; Huang, Z.; Chen, Y.; Bao, Y.; Guo, R.; Xiu, C. Improvement of surface photostability of bamboo scrimber by application of organic UV absorber coatings. J. Wood Sci. 2019, 65, 7. [CrossRef]

(C) 2019 by the authors. Licensee MDPI, Basel, Switzerland. This article is an open access article distributed under the terms and conditions of the Creative Commons Attribution (CC BY) license (http://creativecommons.org/licenses/by/4.0/). 